\title{
A hiatus in the stratosphere?
}

A J Ferraro, M Collins and F H Lambert

College of Engineering, Mathematics and Physical Sciences, University of Exeter, Exeter, UK Correspondence submitted to Nature Climate Change.

Since the turn of the 21st Century there has been a hiatus in the cooling of the lower stratosphere (Fig. 1a). This 'stratospheric hiatus' is happening at the same time as the well-documented hiatus in global surface warming ${ }^{1}$, during a time of increasing carbon dioxide $\left(\mathrm{CO}_{2}\right)$ concentrations ('surface' line in Fig. 1a). Although $\mathrm{CO}_{2}$ acts to warm the surface and troposphere by decreasing outgoing radiative flux at the tropopause, it cools the stratosphere by increasing net infrared emission, so we might expect the continued increase in $\mathrm{CO}_{2}$ concentrations to have produced lower-stratospheric cooling, as observed through much of the depth of the stratosphere ${ }^{2}$. Why, then, do we observe a hiatus in the lower stratosphere?

The answer to this mystery lies in recent changes in lower-stratospheric ozone concentrations. Since the 1970s global total column ozone has been decreasing as a result of human emissions of ozone depleting substances (ODS), primarily chlorofluorocarbons ${ }^{3}$. Ozone absorbs solar and infrared radiation. A decrease in ozone concentrations therefore drives stratospheric cooling ${ }^{2,3}$.

The 1989 Montreal Protocol and subsequent international treaties aimed to combat ozone depletion by reducing human emissions of ODS. The concentration of ODS in the atmosphere has stopped increasing and the stratospheric ozone layer is showing signs of recovering ${ }^{3,4}$.

Thus, the 'stratospheric hiatus' occurs at a unique point in time. The effect of ODS on lower stratospheric temperatures is beginning to decline. In the future, increasing $\mathrm{CO}_{2}$ concentrations will play an important role in lower stratospheric temperatures. This is partly due to the direct effect of $\mathrm{CO}_{2}$ on infrared emission, but also important is the decrease in tropical lower-stratospheric ozone caused by $\mathrm{CO}_{2}$-induced acceleration of the stratospheric Brewer-Dobson circulation bringing ozone-poor air from the troposphere up into the lower stratosphere $^{5}$. For the present, however, the cooling influence of ODS has halted, resulting in a 'hiatus' in stratospheric cooling ${ }^{6-8}$. Higher up in the stratosphere $\mathrm{CO}_{2}$ increases have a stronger cooling influence than lower down because ambient temperatures are higher, so longwave

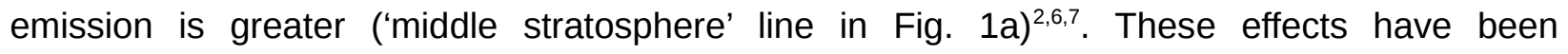
demonstrated in detection and attribution studies of the influences on stratospheric temperature trends $\mathrm{s}^{2,6-8}$. 
The effects of changing concentrations of $\mathrm{CO}_{2}$ and ODS between 14 and $22 \mathrm{~km}$ are illustrated in Fig. 1b. Ozone depletion is responsible for most of the cooling since the 1970s. The effects of $\mathrm{CO}_{2}$ are small at these altitudes because the altitude range of the lower-stratospheric microwave temperature soundings in Fig $1 \mathrm{a}$ includes parts of the tropical upper troposphere, where $\mathrm{CO}_{2}$ has a warming effect. The vertical average of the $\mathrm{CO}_{2}$ effects in the lower stratosphere is therefore small. It is, however, not zero and future large increases in $\mathrm{CO} 2$ concentrations could produce a substantial cooling effect. In the future the concentration of ODS will decrease, acting to warm the lower stratosphere, whereas greenhouse gases will exert a cooling influence.

Changes in the concentration of stratospheric water vapour could also drive stratospheric temperature trends, but measurements of stratospheric water vapour and estimates of its impact on temperatures are uncertain, so this contribution is difficult to determine $e^{2,3,10}$. Changes in the concentration of methane and volcanic aerosols could also influence future lower-stratospheric temperatures.

The hiatus in lower-stratospheric cooling, although coincident with the hiatus in surface warming, has occurred for physical reasons largely unrelated to surface temperature. Our best understanding of the surface hiatus is that it includes a major contribution from internal variability ${ }^{1}$, and that warming will resume in the coming decades. On the other hand the lower-stratospheric hiatus is primarily a forced phenomenon. Since the 1970s the effects of ODS have been the major driver of lower-stratospheric cooling. In the future we expect ODS concentrations to decline and $\mathrm{CO}_{2}$ concentrations to increase. The future of lower stratospheric temperature change will be determined by the balance between these influences (Fig 1b).

\section{Acknowledgements}

This Correspondence was inspired by discussions with third-year Mathematics undergraduates at the University of Exeter: Catherine Serjeant, Rebecca Illingworth, George Beresford, Darius Mehta, Mark Stanton and Alice Clements. We acknowledge the modeling groups for making their simulations available for this analysis, the Chemistry-Climate Model Validation (CCMVal) Activity for WCRP's (World Climate Research Programme) SPARC (Stratospheric Processes and their Role in Climate) project for organizing and coordinating the model data analysis activity, and the British Atmospheric Data Centre (BADC) for collecting and archiving the CCMVal model output. We thank Ted Shepherd helpful comments on the manuscript. This research was supported by the NERC PROBEC project NE/K016016/1. 


\section{References}

1. Fyfe, J. C., Gillett, N. P. \& Zwiers, F. W., Nature Clim. Change 3, 767-769 doi:10.1038/nclimate1972 (2013)

2. Schwarzkopf, M. D. \& Ramaswamy, V., Geophys. Res. Lett. 35, L03705 doi:10.1029/2007GL032489 (2008)

3. World Meteorological Organization (WMO), Scientific Assessment of Ozone Depletion: 2014, World Meteorological Organization, Global Ozone Research and Monitoring Project-Report No. 55, 416 pp., Geneva, Switzerland, 2014

4. Shepherd, T. G. et al. Nature Geosci. 7, 4439-449, doi:10.1038/ngeo2155 (2014)

5. McLandress, C. et al. J. Clim. 27, 8646-8660 doi:10.1175/JCLI-D-14-00232.1 (2014)

6. Stolarski, R. S. et al. J. Clim. 23, 28-41 doi:10.1175/2009JCLI2955.1 (2009)

7. Ramaswamy, V. et al. Science 311, 1138-1141 doi:10.1126/science.1122587 (2006)

8. Gillett, N. P. et al. Atmos. Chem. Phys. 11, 599-609 doi:10.5194/acp-11-599-2011 (2011)

9. Hegglin, M. I. et al. Nature Geosci. 7 768-778 doi:10.1038/ngeo2236 (2014)

10. Morgenstern, O. et al. J. Geophys. Res. 115, D00M02 doi:10.1029/2009JD013728 (2010)

11. Eyring, V. et al. Atmos. Chem. Phys. 10, 9451-9472 doi:10.5194/acp-10-9451-2010 (2010) 


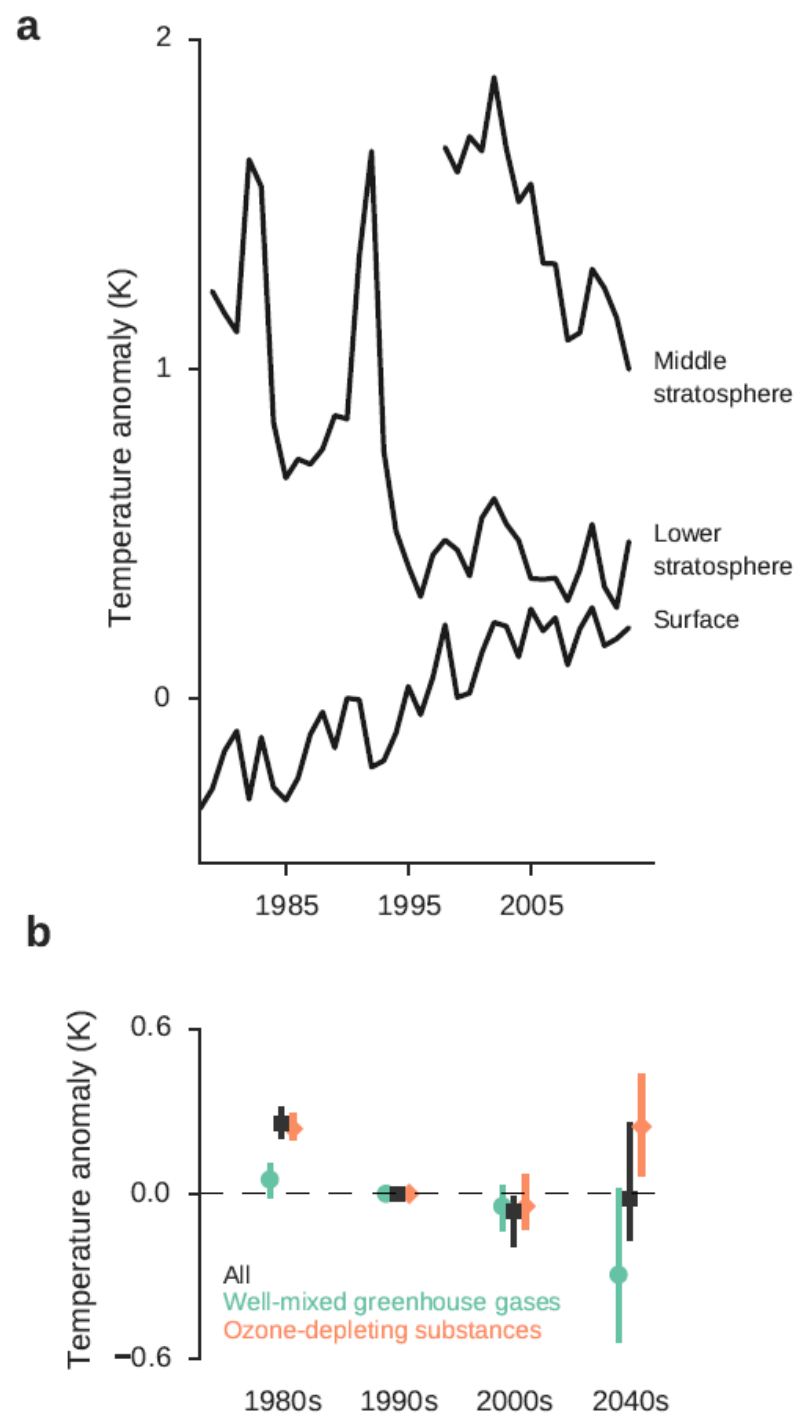

Figure 1: Stratospheric and surface temperature evolution and influences since 1979. a, Annual global-mean surface and stratospheric temperatures. Surface temperatures from from the NASA GISTEMP dataset. Stratospheric temperatures are derived from measurements from different channels of the Microwave Sounding Unit, processed by Remote Sensing systems: lower stratosphere (TLS; approximately 14-22 km) and upper-middle stratosphere (C13; approximately 30-40 km). Temperature anomaly series are offset from zero for clarity. $\mathbf{b}$, Decadal-mean temperatures simulated by seven chemistry-climate models between 14-22 km relative to the period 1990-1999 for the CCMVal-2 scenario REF-B2 ${ }^{10}$ (All), which uses the IPCC SRES A1B greenhouse gas scenario. The 'greenhouse gases' scenario is the same as REF-B2 but has fixed ODS, and the 'ozone-depleting substances' scenario has fixed GHGs ${ }^{11}$. Markers denote the multimodel mean and bars indicate the intermodel range. Models used: CCSRNIES, CMAM, LMDZrepro, MRI, SOCOL, UMSLIMCAT and WACCM. 